\title{
Heterotopic pregnancy after in vitro fertilization / intracytoplasmic sperm injection: case report
}

\section{Introduction}

Heterotypic pregnancy is a rare cause of acute abdomen, characterized by the coexistence of an intrauterine and an ectopic gestation simultaneously. ${ }^{1-6}$ In the early stages, the diagnosis is challenging, as a consequence of the existence of the concomitant intrauterine gestation. ${ }^{5}$

The prognosis depends mainly on the early diagnosis and the surgical technique used in the treatment. ${ }^{5}$ Studies show that $35 \%$ of the patients evolve with loss of the intrauterine pregnancy ${ }^{7}$ and $26.6 \%$ of the patients have premature labor. ${ }^{4}$ In a series of cases, the live birth rate was $66.7 \%{ }^{4}{ }^{4}$ This article aims to report a case of a patient diagnosed with tubal heterotopic pregnancy after in vitro fertilization/ Intracytoplasmic injection (IVF/ICSI). The patient was surgically treated and progressed with the viability of intrauterine gestation, and she was followed up until the delivery.

\section{Case report}

A patient of 36 years old, with previous history of infertility for 5 years due to polycystic ovary syndrome underwent some unsuccessfully low-complexity infertility treatments, then she underwent IVF/ICSI in October 2015. The patient opted for freezingall embryos for subsequent transfer. In June 2016, two frozen-thawed embryos were transferred in the blastocyst stage. Twelve days after the embryo transfer, the pregnancy test using quantitative Human Beta-Gonadotrophin Assay (beta-hCG) resulted in $462.91 \mathrm{mIU} / \mathrm{mL}$. Two days later she presented severe pain in the lower abdomen and transvaginal bleeding.

On physical examination, the patient was hemodynamically stable and there were nosigns of peritoneal irritation. At the vaginal exam, the cervix was closed. Serum concentrations of beta-hCG, with a 48 hour interval, increased at a rate of $51 \%$. The patient progressed with the improvement of pain and bleeding.

Twelve days after performing the first beta- $\mathrm{hCG}$, a transvaginal ultrasonography (USTV) was performed, which showed topical gestation with a single embryo presenting heartbeats and biometry compatible with the gestational age of 7 weeks and one day (Figure 1); there was also a simple cyst in right ovary (volume $33.8 \mathrm{~cm}^{3}$ ) and an image in the right adnexal region suggestive of ectopic pregnancy (Figure 2).

On the same day of the USTV, the patient underwent exploratory laparotomy. There was a ruptured ectopic pregnancy in the right side fallopian tube, with a small amount of blood in the abdominal cavity and a simple cyst in the right ovary (which ruptured during the surgical procedure). Salpingectomy and right oophoroplasty were performed without complications. USTV performed in the day after the surgery showed intrauterine live embryo. The pregnancy progressed uneventfully. The patient delivered a healthy baby after 38 weeks and 6 days of pregnancy with good vitality and weighing $3,605 \mathrm{~kg}$.
Special Issue - 2018

Marcela de Alencar Coelho Net,' Iris Gondim Novais, ${ }^{2}$ Sofia Fernandes Pinto Maia, ${ }^{2}$ Davi Carneiro de Brito ${ }^{2}$

'Department of Obstetrics and Gynecology, Ribeirao Preto Medical School, University of Sao Paulo, Ribeirao Preto, Brazil 2Faculty of Medicine Estácio of Juazeiro do Norte, Juazeiro do Norte, Brazil

Correspondence: Marcela de Alencar Coelho Neto, Department of Obstetrics and Gynecology, Ribeirao Preto Medical School, University of Sao Paulo, Ribeirao Preto, Brazil, Tel +55(88)9925I-948I, Email marcelalencar@hotmail.com

Received: November 16, 2017| Published: November 30, 2018

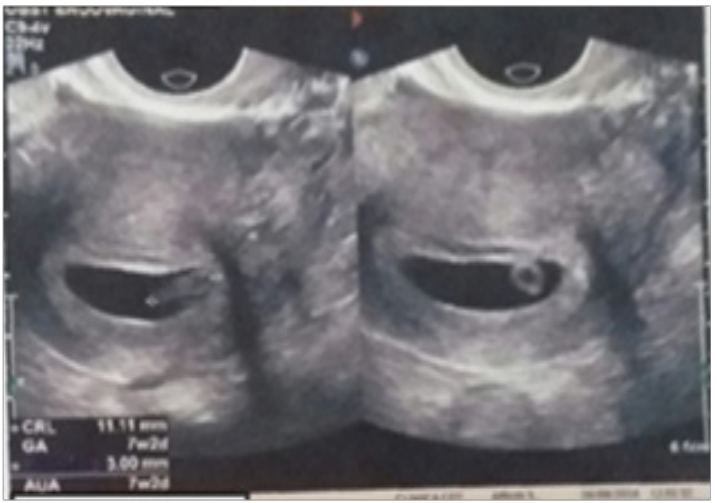

Source: Marcelo Pierre Medical Center Archive.

Figure I Uterus is containing gestational sac inside. IA-Embryo. IB-Vitelline vesicle.

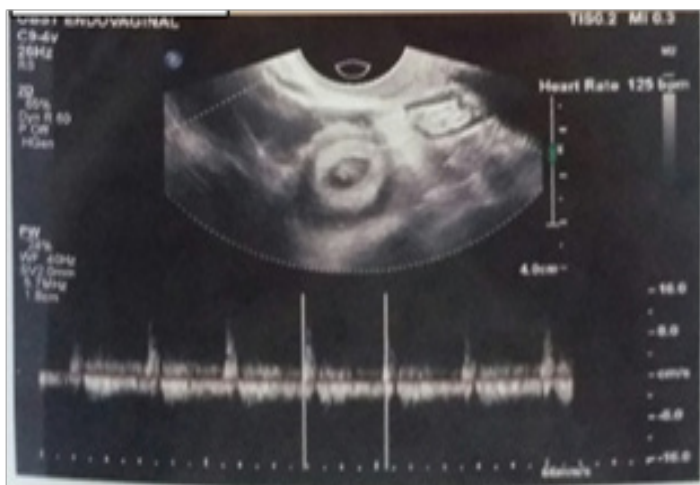

Source: Marcelo Pierre Medical Center Archive.

Figure 2 Adnexal image suggestive of ectopic pregnancy, characterized by embryo presenting heartbeats. 


\section{Discussion}

Although it is a rare pathology in spontaneous pregnancies $(1: 30,000)$, its incidence has increased after the use of assisted reproduction techniques (ART)(1:100) ${ }^{6,8,9}$ Even so, it is an infrequent condition what justifies the report of this case. There are factors that reduce the risk of heterotopic pregnancy after IVF, such as reduced amount of embryos transferred (two or less), correct placement of the catheter during the transfer (less than $5 \mathrm{~mm}$ from the uterine fundus), loading the catheter with small volume, transfer of the embryo on the third day of evolution and the use of cryopreserved embryos. ${ }^{10,11}$ In the present case, the patient received two embryos in the blastocyst stage.

The symptomatology of the heterotopic pregnancy is nonspecific and may be asymptomatic in $10 \%$ of cases ${ }^{12}$ or present with symptoms such as amenorrhea, transvaginal bleeding and pain, as reported by the patient in the present case. The serum levels of Beta-hCG usually do not help in the diagnosis of heterotopic gestation, since due to the coexistence of intrauterine gestation, they will be elevated. ${ }^{5}$ In the present case, the positivity of beta-hCG and its increasing values within 48 hours speak in favor of an intrauterine pregnancy evolving within normal, where beta-hCG concentrations $>1500-2000 \mathrm{mIU} / \mathrm{mL}$ are expected with an increase of $50-66 \%$ in 48 hours. $^{12}$

In patients at high risk for ectopic or heterotopic pregnancy, especially those who underwent assisted reproduction treatments, USTV screening should be performed around 4 weeks after embryo transfer. ${ }^{13}$ Thus the diagnosis of heterotopic pregnancy is usually made earlier. The treatment aims to maintain the intrauterine pregnancy and remove the extrauterine pregnancy as soon as possible. ${ }^{14}$ The surgical treatment consists in the removal of extrauterine gestation, and it can be by laparoscopy or laparotomy. ${ }^{15}$ The patient underwent right salpingectomy via laparotomy, the gold-standard technique for ectopictubal pregnancy. ${ }^{16}$

Although the rate of miscarriage and preterm delivery of intrauterine pregnancy is higher when the resolution of extrauterine pregnancy is by laparotomy, the patient in this report presented a good prognosis for intrauterine pregnancy. This was mainly due to obtaining an early diagnosis of heterotopic pregnancy and because the patient did not present hemodynamic instability.

This work had as main limitation its design because it is a report of an isolated case. The monitoring of the patient until the delivery allowed the obtain the main outcome of studies in reproductive medicine, to evaluate if there was a live birth, which is a relevant point of this study.

\section{Conclusion}

The occurrence of heterotopic gestation has become increasingly frequent. Given this context, it is important to consider this diagnostic hypothesis in patients presenting risk factors. Once this is a condition that manifests through nonspecific symptoms, and there is a concomitant intrauterine pregnancy, early diagnosis is challenging. However, monitoring adequately patients submitted to IVF/ICSI has facilitated diagnosis and decreased the rate of maternal and fetal death. Early surgical treatment, preferably through salpingec to my, contributes to the preservation of intrauterine pregnancy.

\section{Acknowledgements}

None.

\section{Conflict of interest}

The author declares no conflict of interest.

\section{References}

1. Yu Y, Xu W, Xie Z, et al. Management and outcome of 25 heterotopic pregnancies in Zhejiang. Eur J Obstet Gynecol Reprod Biol. 2014;180:157-161.

2. Donadio Nilka Fernandes, Donadio Nilson, Martins Priscila Takahashi, et al. Gestação heterotópica: possibilidade diagnóstica após fertilização in vitro. A propósito de um caso. Rev. Bras. Ginecol Obstet Sep. 2008;30(9):466-469.

3. Robert W, De Voe, Joseph Hyde Pratt. Simultaneous intrauterine and extrauterine pregnancy. Am J Obstet Gynecol. 1948;56(6):1119-11126.

4. David Soriano, Danielle Vicus, Ron Schonman, et al. Long-term Outcome aftenlaparoscopic treatment of heterotopic pregnancy: 19 cases. $J$ Minim Invasive Gynecol. 2010;17(3):321-324.

5. Jeon JH, Hwang YI, Shin IH, et al. The risk Factors and pregnancy outcomes of 48 cases of heterotopic pregnancy from a single center. $J$ Konean Med Sci. 2016;31(7):1094-1099.

6. Cheng Kuan Lin, Kuo Chang Wen, Pi Lin Sung, et al. Hetrotopic triplet pregnancy with an intravterine, a trebal and a cenvical gestation following in vitro fertilization and embryo tranfen. Taiw J obstet Gynecol. 2013;52:287-289.

7. Aranda F Mireia, González R María Inmaculada, Ruiz M Fernando, et al. Gestación heterotópica en dos casos de embarazos espontáneos. Rev chil obstet Ginecol. 2012;77(6):444-446.

8. Jin Bo Li, Ling Zhi Kong, Jian Bo Yang, et al. Management of heteropic pregnancy: experience from 1 tentiany Medical Center. Medicine. 2016;95(5):1-7.

9. Jeong Min Eom, Joong Sub Choi, Jung Hwa Ko, et al. Sungical and obstetric outcomes of laparoscopic management for women with heterotopic pregnancy. J Obstet Gynaecol Res. 2013;39(12):1580-1586.

10. Tarik Kassem Saidah, Waldemar Naves do Amaral, Luiz Augusto Batista, et al. Prenhez ectópica em fertilização assistida clássica e injeção espermática intracitoplasmática. Femina. 2011;39(9):429-432.

11. Radmila Sparić, Snežana Buzadžić, Rajka Argirović, et al. Heterotopic pregnancy aften in vitro fertilization and embryo transfer: a case repost. Srp Arh Celok Lek. 2012;140(7-8):511-514.

12. Kirk E, Bourne T. Diagnosés of ectopic pregnancy with ultrasound. Best practice e Reseanch clinical obstetrics and Gynecology. 2009;23:501508.

13. Veli Mihmanli, Ahmet Kilickaya, Nur Cetinkaya, et al. Spontaneous heterotopic pregnancy presenting with hemoperitoncum. The J emerge med. 2016;50(1):44-46.

14. Ugurlucan FG, Bastu E, Dogan M, et al. Management of cesarean heterotopic pregnancy with transvaginal ultrasound-guided potassium chloride injection and gestational sac aspiration, and review of the literature. J Minim Invasive Gynecol. 2012;19(5):671-673.

15. A Santamaría Marín, C Monroy Gómez. Gestación heterotópica: uma causa infrecuente de abdomen agudo. Carta Clinica. 2016;42(4):270271.

16. Mol F. Salpingotomy versus salpingectomy in women with tubal pregnancy (ESEP Study): an open-label, multicenter, randomised controlled trial. The lancet. 2014;383(9927):1483-1489. 